\title{
Efeito de meios de cultura e fatores físicos no crescimento e esporulação de Alternaria dauci e A. solani*
}

\author{
Pablo Pulz; Nelson S. Massola Jr.
}

Departamento de Entomologia, Fitopatologia e Zoologia Agrícola - ESALQ/USP, Caixa Postal 9, 13400-000 - Piracicaba - SP, Brasil. nmassola@esalq.usp.br. * Parte da dissertação de mestrado do primeiro autor.

Autor para correspondência: Nelson S. Massola Jr.

Data de chegada: 10/07/2007. Aceito para publicação em: 04/12/2008

\section{RESUMO}

Pulz, P.; Massola Jr., N.S. Efeito de meios de cultura e fatores físicos no crescimento e esporulação de Alternaria dauci e A. solani. Summa Phytopathologica, v.35, n.2, p.121-126, 2009

Alternaria dauci e Alternaria solani são espécies reconhecidamente difíceis de esporular em meios de cultura. Este trabalho teve o objetivo de verificar a influência de alguns meios de cultura e fatores fisicos sobre o crescimento micelial e a esporulação dessas espécies. Testaram-se os meios de cultura BDA, Aveia e V8; temperaturas $\left(15^{\circ} \mathrm{C}, 20^{\circ} \mathrm{C}, 25^{\circ} \mathrm{C}, 30^{\circ} \mathrm{C}\right.$ e $\left.35^{\circ} \mathrm{C}\right)$ comprimentos de onda da luz durante a incubação (amarelo, azul, branco, NUV, verde e vermelho); tipos de injúria aplicados à colônia (raspagem, UV, irradiação de microondas, e temperatura de $100{ }^{\circ} \mathrm{C}$ ) e fotoperíodos (luz / escuro, respectivamente, de $24 \mathrm{~h}$ $/ 0 \mathrm{~h}, 22 \mathrm{~h} / 2 \mathrm{~h}, 17 \mathrm{~h} / 7 \mathrm{~h}, 12 \mathrm{~h} / 12 \mathrm{~h}, 7 \mathrm{~h} / 17 \mathrm{~h}, 2 \mathrm{~h} / 22$ e $0 \mathrm{~h}$
/ $24 \mathrm{~h}$ ). O método desenvolvido neste trabalho foi comparado ao tradicionalmente utilizado (BDA, $25^{\circ} \mathrm{C}, 12 \mathrm{~h}$ luz branca / $12 \mathrm{~h}$ escuro e raspagem da colônia). O meio V8-ágar, temperatura de 25 ${ }^{\circ} \mathrm{C}$, luz NUV e raspagem das colônias exerceram influência mais marcante no crescimento e esporulação. O fotoperíodo $12 \mathrm{~h}$ luz NUV / $12 \mathrm{~h}$ escuro foi o que mais estimulou a esporulação. Observou-se que, de modo geral, períodos de escuro maiores que os períodos de luz, aplicados após injúria da colônia, favoreceram a esporulação. O método desenvolvido mostrou-se nitidamente superior ao tradicionalmente utilizado, para crescimento e esporulação de ambas as espécies.

Palavras-chave adicionais: Fungo fitopatogênico, produção de inoculo, luz, temperatura

\section{ABSTRACT}

Pulz, P.; Massola Jr., N.S. Effect of culture media and physical factors on growth and sporulation of Alternaria dauci and A. solani. Summa Phytopathologica, v.35, n.2, p.121-126, 2009

Alternaria dauci and $A$. solani are fungal species known for difficult sporulation in culture media. This study had the objective of verifying the influence of some physical factors on mycelia growth and sporulation of these two species. Culture media (BDA, oat and V8), temperature $\left(15^{\circ} \mathrm{C}, 20^{\circ} \mathrm{C}, 25^{\circ} \mathrm{C}, 30^{\circ} \mathrm{C}\right.$ and $\left.35^{\circ} \mathrm{C}\right)$, light wavelengths during incubation (yellow, blue, white, NUV, green, and red), injury types applied to the colony (scratching, UV, microwave irradiation, and temperature of $100{ }^{\circ} \mathrm{C}$ ) and photoperiods (light / dark, respectively, of $24 \mathrm{~h} / 0 \mathrm{~h}, 22 \mathrm{~h} / 2 \mathrm{~h}, 17 \mathrm{~h} / 7 \mathrm{~h}, 12 \mathrm{~h} / 12 \mathrm{~h}, 7 \mathrm{~h} / 17 \mathrm{~h}, 2 \mathrm{~h} / 22$ $\mathrm{h}$ and $0 \mathrm{~h} / 24 \mathrm{~h}$ ) were tested. The method developed in this study was compared to the traditional procedure (BDA, $25^{\circ} \mathrm{C}, 12 \mathrm{~h}$ white / 12 $\mathrm{h}$ dark light and scratching of the colony). V8-agar medium, temperature of $25^{\circ} \mathrm{C}$, NUV light and scratching of the colonies had a marked effect on growth and sporulation. The $12 \mathrm{~h}$ light / $12 \mathrm{~h}$ dark photoperiod stimulated sporulation most. In general, longer dark than light periods after the injury of the colony favored sporulation. The developed procedure is clearly superior to the traditional method for growth and sporulation of both species.

Keywords: Phytopathogenic fungi, inoculum production, light, temperature

A queima das folhas da cenoura e a pinta-preta das solanáceas são doenças causadas por fungos das espécies Alternaria dauci (J.G. Kuhn) J.W. Groves \& Skolko e A. solani Sorauer, respectivamente, e causam grandes danos às culturas $(10,18,19)$.

Diante do cultivo intenso da cenoura e de algumas solanáceas, há a necessidade de desenvolvimento de cultivares com resistência às doenças e adaptações às diferentes condições climáticas. Contudo, programas específicos de melhoramento que visam desenvolver cultivares de cenoura e tomate resistentes a esses fungos enfrentam dificuldade na obtenção de esporos de $A$. dauci e $A$. solani em quantidades adequadas para inoculações, visando selecionar genótipos.
Além da grande variabilidade em meio de cultura, estas espécies também se mostram variáveis na patogenicidade $(5,17)$, o que torna necessário o uso de vários isolados nos programas de melhoramento. Dificuldade de esporulação in vitro é típica em espécies patogênicas que produzem esporos grandes e solitários (16).

Sabe-se, também, que as condições requeridas na fase reprodutiva são distintas das requeridas para o crescimento micelial para várias espécies de Alternaria. Além disso, há a necessidade de indução por fatores injuriantes da colônia para que a esporulação ocorra, como raspagem do micélio aéreo e subseqüente exposição à luz branca ou ultravioleta próximo (NUV) $(3,6,11,16,23)$. No entanto, poucos 
são os estudos sobre a influência do meio de cultura, temperatura, comprimento de onda da luz utilizada e fatores injuriantes sobre o crescimento micelial e esporulação de $A$. dauci e $A$. solani.

Fancelli (5), trabalhando com isolados de $A$. solani relatou que os isolados provenientes da batateira esporularam naturalmente em meio BDA a $22^{\circ} \mathrm{C}$, enquanto que os isolados provenientes do tomateiro necessitaram de injúria no micélio para esporular. Além disso, os isolados do tomateiro mostraram maior crescimento micelial em BDA que os isolados da batateira. Strandberg (20) verificou o efeito de meios de cultura e alguns fatores físicos no crescimento e esporulação de $A$. dauci. O autor mostrou que essa espécie apresentou máximo crescimento micelial em $\mathrm{pH}$ 6,0, porém, a esporulação máxima foi $\mathrm{em} \mathrm{pH} 7,0$. A esporulação ocorreu em ampla faixa de temperatura $\left(15^{\circ} \mathrm{C}\right.$ a $\left.30^{\circ} \mathrm{C}\right)$, porém, necessitou de estímulo luminoso mínimo de $4 \mathrm{~h}$ de luz para ocorrer. Fancelli \& Kimati (6) testaram os meios BDA, Czapeck e um meio à base de folhas de cenoura, além do efeito da luz fluorescente no crescimento e na esporulação de $A$. solani $\mathrm{e}$ A. dauci. Concluíram que, tanto a composição e concentração do meio de cultivo quanto a luz fluorescente, desempenharam importante papel na esporulação do fungo. A luz utilizada durante a incubação tem efeito marcante na esporulação de espécies de Alternaria, exercendo papel estimulante ou inibidor (16). Honda e Nemoto (8) verificaram que a luz NUV estimulou a formação de conidióforos em $A$. solani. No entanto, a produção subseqüente de conídios foi inibida por exposição das colônias à luz azul. Estudos mais detalhados sobre o efeito destes e de outros fatores poderiam contribuir para facilitar ou aumentar a esporulação de $A$. dauci e $A$. solani, tornando mais eficiente a obtenção de maiores quantidades de esporos para atender os trabalhos de inoculação que visam desenvolver medidas de controle para essas doenças.

Sendo assim, os objetivos deste estudo foram identificar o melhor meio de cultura e a melhor temperatura para o crescimento micelial de A. dauci $\mathrm{e}$ A. solani; identificar o melhor comprimento de onda luminosa para o crescimento micelial e esporulação; identificar o melhor fator injuriante da colônia para a esporulação; identificar o melhor fotoperíodo, aplicado após a indução, para a esporulação e comparar as melhores condições, acima descritas, com o tratamento convencional, para diversos isolados de A. dauci e A. solani.

\section{MATERIAL E MÉTODOS}

Um isolado de $A$. dauci e outro de $A$. solani, ambos provenientes de Londrina, PR, foram utilizados nos ensaios para verificar os efeitos da temperatura, meio de cultura, comprimentos de onda usados na incubação, fatores injuriantes do micélio e fotoperíodo aplicado após a indução da esporulação. No ensaio que visou comparar a metodologia tradicional para crescimento e esporulação com a desenvolvida neste estudo, utilizaram-se cinco isolados de $A$. dauci e cinco de $A$. solani, provenientes dos Estados de SP e PR. Todos os isolados foram obtidos da coleção do Laboratório de Micologia do Departamento de Entomologia, Fitopatologia e Zoologia Agrícola da Escola Superior de Agricultura "Luiz de Queiroz" (Piracicaba) e da empresa Sakata Seed Sudamerica LTDA.

\section{Efeito do meio de cultura e da temperatura no crescimento} micelial

Foram utilizados os meios de cultura de Aveia (21), BDA (4) e V8ágar (14). Discos de $6 \mathrm{~mm}$ de diâmetro foram retirados da borda de colônias de $A$. dauci e $A$. solani cultivadas nos respectivos meios e transferidos para o centro de cada placa de Petri, em cinco repetições. A incubação ocorreu no escuro, sob temperaturas de $15^{\circ} \mathrm{C}, 20^{\circ} \mathrm{C}, 25^{\circ} \mathrm{C}, 30^{\circ} \mathrm{C}$ e $35^{\circ} \mathrm{C}$ $\left( \pm 1^{\circ} \mathrm{C}\right)$. A avaliação do crescimento micelial (cm/dia) baseou-se na determinação da velocidade de crescimento, por meio de medições do diâmetro das colônias, em dois eixos perpendiculares entre si, durante 11 dias de incubação ou até que, em uma das placas, o micélio já tivesse tomado por completo a superfície do meio de cultura.

\section{Efeito de diferentes fontes de luz no crescimento e esporulação}

O experimento foi realizado após a seleção do melhor meio de cultura e temperatura observados no experimento anterior. Os mesmos isolados foram repicados para placas de Petri contendo o meio V8ágar e incubados sob diferentes espectros de radiação luminosa, proporcionados por lâmpadas fluorescentes comerciais que forneceram comprimentos de onda NUV (luz negra), azul, verde, amarelo, vermelho e branco. As placas permaneceram a $30 \mathrm{~cm}$ das lâmpadas, conforme preconizado por Leach (11). A distribuição espectral de energia das lâmpadas fluorescentes e a determinação da iluminância foram realizadas antes do início dos experimentos, em espectrofluorímetro Perkin Elmer $^{\circledR}$, modelo 2555 e luxímetro Instrutherm ${ }^{\circledR}$, modelo LD-204, respectivamente. Os intervalos dos comprimentos de onda (çm) e iluminância (lux), respectivamente, foram: NUV (310-440, 25), Azul (450-510, 352), Verde (480-590, 725), Amarelo (570-630, 1430) e Vermelho $(610-670,140)$. Para a luz branca, foram obtidos diversos picos de absorção, em diferentes regiões do espectro $(315,360,410$, $620,627$ e 670$)$, sendo 625 çm e 670 çm, os maiores picos observados. A iluminância medida para a luz branca foi de 2250 lux.

As colônias foram incubadas de oito a 10 dias, em temperatura de $25{ }^{\circ} \mathrm{C} \pm 1{ }^{\circ} \mathrm{C}$. O crescimento micelial foi avaliado conforme descrito anteriormente. Em seguida, as placas foram divididas em dois grupos. Todas as placas de um dos grupos sofreram raspagem do micélio aéreo com lâmina de vidro. As colônias do outro grupo foram mantidas íntegras. Após este procedimento, os dois grupos foram submetidos às mesmas condições de radiação empregadas no crescimento micelial, sob fotoperíodo de 12 horas na luz e 12 horas no escuro, respectivamente, por 48 horas. Os conídios foram coletados em 15 $\mathrm{mL}$ de água destilada esterilizada, por raspagem da colônia com pincel (6). A quantificação de conídios da suspensão foi realizada em câmara de Neubauer e expressa em conídios $/ \mathrm{cm}^{2}$ de colônia. O experimento foi inteiramente casualizado, com cinco repetições (placas) por tratamento.

\section{Efeito de diferentes injúrias da colônia na esporulação}

O meio de cultura, temperatura e espectro de radiação utilizados nesta etapa foram aqueles dos melhores tratamentos determinados nos experimentos anteriores. Os fungos foram incubados nessas condições por sete dias e, então, submetidos ao fator injuriante, com subseqüente exposição a fotoperíodo de 12 horas na luz (com o mesmo espectro de radiação usado na incubação) e 12 horas no escuro, por 48 horas.

Como fatores injuriantes da colônia, utilizaram-se (i) radiação de microondas [forno de microondas marca Panasonic, modelo NN-S62B, capacidade de $35 \mathrm{~L}$, em potência mínima $(97,6 \mathrm{~W})$ e freqüência de $2450 \mathrm{MHz}$; (ii) temperatura de $100^{\circ} \mathrm{C}$, utilizando estufa (marca Ação Científica, modelo EL 1.1, potência $465 \mathrm{~W}$ e com controle digital de temperatura) regulada para $100^{\circ} \mathrm{C} \pm 2{ }^{\circ} \mathrm{C}$ e; (iii) radiação $U V$, por meio de exposição (a $30 \mathrm{~cm}$ de distância) à lâmpada UV (marca Toshiba, modelo GL 30T8, potência $30 \mathrm{~W}$ ) acoplada no interior de câmara de fluxo laminar. $\mathrm{O}$ valor da potência utilizada no forno de microondas foi calculado segundo Kingston \& Jassie (9). As potências da estufa e 
da lâmpada UV foram obtidas nos manuais dos respectivos equipamentos.

Testes preliminares foram realizados anteriormente para se determinar o tempo de inativação micelial dos isolados de $A$. dauci e $A$. solani utilizados no ensaio, quando submetidos a essas condições. Para a aplicação do fator injuriante, elegeu-se o período de tempo imediatamente anterior ao ponto de inativação total do micélio, admitindo-se que neste ponto o micélio havia sido bastante injuriado. Para ambas as espécies fúngicas, o tempo estabelecido para a injúria com as radiações de microondas e UV foi de $25 \mathrm{~s}$ e $20 \mathrm{~min}$, respectivamente. Para a injúria por meio de exposição à temperatura de $100^{\circ} \mathrm{C}$, os períodos de tempo determinados foram de 4 min para $A$. solani e 5 min para $A$. dauci. Além desses fatores, também foi aplicada a raspagem do micélio aéreo, método tradicionalmente utilizado, como tratamento testemunha. A esporulação foi avaliada de maneira idêntica à descrita anteriormente.

Efeito do fotoperíodo aplicado após a injúria da colônia na esporulação

Após a seleção das melhores condições observadas anteriormente, discos de seis mm de diâmetro das colônias de $A$. dauci e $A$. solani foram transferidos para placas de Petri e incubados, de sete a oito dias, sob luz contínua. A seguir, as colônias passaram por raspagem do micélio aéreo e submetidas a fotoperíodos (luz / escuro, respectivamente) por $24 \mathrm{~h} / 0 \mathrm{~h}, 22 \mathrm{~h} / 2 \mathrm{~h}, 17 \mathrm{~h} / 7 \mathrm{~h}, 12 \mathrm{~h} / 12 \mathrm{~h}, 7 \mathrm{~h}$ $/ 17$ h, 2 h / 22 h e 0 h / 24 h. A avaliação da esporulação foi realizada de maneira já mencionada anteriormente. O experimento foi inteiramente casualizado, com cinco repetições (placas) por tratamento.

Comparação entre o método tradicional e o desenvolvido neste estudo, para diferentes isolados de Alternaria dauci e Alternaria solani

Neste experimento, objetivou-se comparar a metodologia tradicional com a desenvolvida nesse estudo, em diversos isolados dos fungos. Foram utilizados os isolados $\mathrm{AD} 22, \mathrm{AD} 24, \mathrm{AD} 28, \mathrm{AD}$ 33, AD 42 (A. dauci) e AS 03, AS 05, AS 20, AS 21e AS 22 (A. solani), provenientes dos Estados de SP e PR. Estes isolados encontram-se depositados, com estes mesmos códigos, na micoteca do Setor de Fitopatologia da ESALQ.

Discos de micélio com seis $\mathrm{mm}$ de diâmetro foram transferidos para o centro de placas de Petri contendo o meio BDA e o meio V8ágar. No experimento utilizando a metodologia tradicional, placas contendo o meio BDA foram incubadas de sete a 11 dias, em temperatura de $25{ }^{\circ} \mathrm{C} \pm 1{ }^{\circ} \mathrm{C}$, sob luz branca contínua. Para o outro experimento, placas contendo o meio V8-ágar foram incubadas durante o mesmo tempo e temperatura, sob luz NUV contínua. O crescimento foi avaliado conforme descrito anteriormente. A injúria aplicada às colônias foi a raspagem do micélio aéreo, metodologia utilizada tradicionalmente e, também, o melhor tratamento observado nesse estudo para ambas as espécies. A avaliação da esporulação foi realizada conforme citado anteriormente.

$\mathrm{O}$ experimento foi inteiramente casualizado, com cinco repetições (placas) por tratamento.

\section{RESULTADOS E DISCUSSÃO}

Efeito do meio de cultura e da temperatura no crescimento micelial

O crescimento micelial de $A$. dauci e A.solani foi influenciado pelo meio de cultura e pela temperatura. O meio V8-ágar se destacou para ambas as espécies (Figura 1). Nesse meio, a temperatura ótima de crescimento, para ambas as espécies, foi de $25^{\circ} \mathrm{C}$. A melhor temperatura observada foi a mesma citada para muitas outras espécies de fungos (7). O meio BDA, tradicionalmente utilizado em estudos de crescimento e esporulação de Alternaria, proporcionou as menores velocidades de crescimento para ambas as espécies. O meio de aveia proporcionou desempenho similar ao observado em V8-ágar para $A$. solani, com máximo de crescimento a $20^{\circ} \mathrm{C}$ e $25^{\circ} \mathrm{C}$. Porém, para $A$. dauci, diferentemente do que ocorreu com o meio V8-ágar, este meio proporcionou crescimento máximo a $20^{\circ} \mathrm{C}$, mostrando que a composição do meio de cultivo interage com o fator temperatura no crescimento dessa espécie.

Miller (14) já havia relatado os benefícios do meio V8-ágar no crescimento e esporulação das espécies aqui estudadas, bem como de outras espécies fúngicas. Queiroz et al. (15), estudando o comportamento de A. brasiliensis Queiroz, Muniz \& Menezes em 20 meios de cultura, observaram que o crescimento e esporulação dessa espécie foram significativamente superiores em meio V8-ágar quando comparado com os outros meios empregados no estudo. Assim, o meio V8-ágar ainda se constitui a melhor opção para estudos de crescimento e esporulação destas e de outras espécies de Alternaria e outros fungos, quando comparado com meios sintéticos.
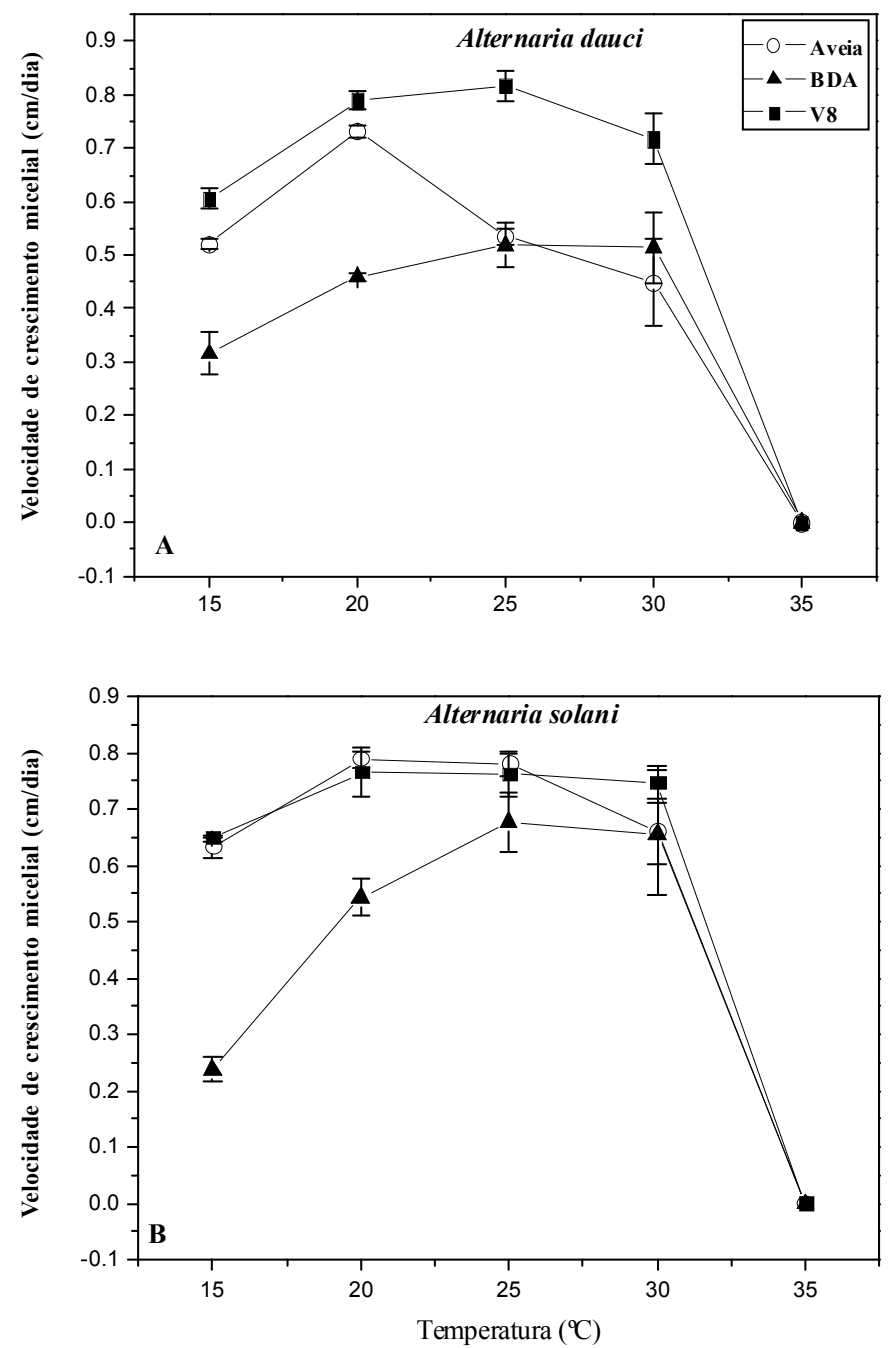

Figura 1 - Efeito da temperatura e meio de cultura no crescimento micelial de Alternaria dauci (A) e Alternaria solani (B). As barras representam o erro padrão. 
Efeito de diferentes fontes de luz no crescimento e esporulação

Entre as duas espécies estudadas, o crescimento micelial de $A$. dauci sofreu influência mais marcante dos comprimentos de onda utilizados na incubação, atingiu maiores valores quando foram utilizadas luz NUV e branca. Ligeiro efeito negativo da luz verde foi observado para essa espécie (Figura 2A). Conforme Strandberg (20), comprimentos de onda maiores, acima de $600 \mathrm{~nm}$, parecem ser mais efetivos na estimulação do crescimento micelial de $A$. dauci. Para $A$. solani, não houve efeito muito pronunciado dos comprimentos de onda no crescimento micelial, exceto por um pequeno estímulo da luz azul, indicando que esta espécie é menos sensível a este fator que $A$. dauci.

A esporulação foi ainda mais afetada pelas luzes utilizadas, principalmente para A. solani. Para esta espécie, esporulação máxima foi obtida sob as luzes NUV e branca, com intensa inibição sob luz azul. Neste ensaio, a esporulação do isolado de $A$. dauci foi mínima, ocorrendo somente quando foi utilizada luz NUV, confirmando o efeito positivo deste comprimento de onda (Figura 2B). A grande variabilidade de isolados dessas espécies em meio de cultura, no que concerne à esporulação, é consenso entre muitos autores. Alguns isolados podem se manter esporulantes por anos em meio de cultura, mesmo após muitos repiques e, outros podem perder a capacidade de esporulação após curto período em cultura ou única passagem por um meio de cultura $(16,20)$.

Somente as placas que tiveram o micélio aéreo removido com lâmina de vidro exibiram esporulação, confirmando a necessidade de injúrias no micélio.

Segundo Rotem (16), não há um consenso sobre o efeito da luz no mecanismo bioquímico da formação dos conidióforos de Alternaria. Mas é certo que irradiações de culturas fúngicas induzem a formação de novos ácidos nucléicos ou substâncias esporogênicas (22). O intervalo correspondente à luz azul foi identificado como altamente inibidor da esporulação em A. solani, indicando que a fotoinibição da formação conidial é uma resposta biológica à luz azul. A baixa esporulação observada em luz azul, verde, amarela e vermelha está de acordo com os resultados obtidos por Honda \& Nemoto (8).

Efeito de diferentes fatores injuriantes da colônia na esporulação

A raspagem do micélio aéreo foi o fator injuriante que promoveu a maior esporulação, tanto para $A$. dauci quanto para $A$. solani. A injúria com temperatura de $100{ }^{\circ} \mathrm{C}$ apresentou pequena influência na esporulação das duas espécies. Apesar de não ter causado inativação do micélio, a alta temperatura pode, segundo Lehninger (12), ter alterado algumas enzimas que participam do processo de esporulação, sem ter afetado a viabilidade do micélio. Essa talvez seja a razão da baixa esporulação das duas espécies neste tratamento. No entanto, a luz UV e a irradiação com microondas exerceram grande influência na esporulação de $A$. dauci, não diferindo entre si. Mas, para $A$. solani, a utilização de luz UV como fator injuriante da colônia teve uma influência negativa, não levando à produção de conídios (Figura 3 ).

Macromoléculas biológicas essenciais são alvos de radiação UV, que é fortemente absorvida pelas células e ocasiona uma variedade de fotoprodutos incompatíveis com a função celular (1). Há uma relação muito tênue entre os efeitos da luz UV na esporulação e o efeito danoso desse tipo de radiação em ácidos nucléicos, ainda o principal alvo dos efeitos metabólicos. Esse tipo de radiação pode ter afetado uma série de processos bioquímicos que podem ter sido inativados temporária ou permanentemente e ter afetado a esporogênese de $A$.
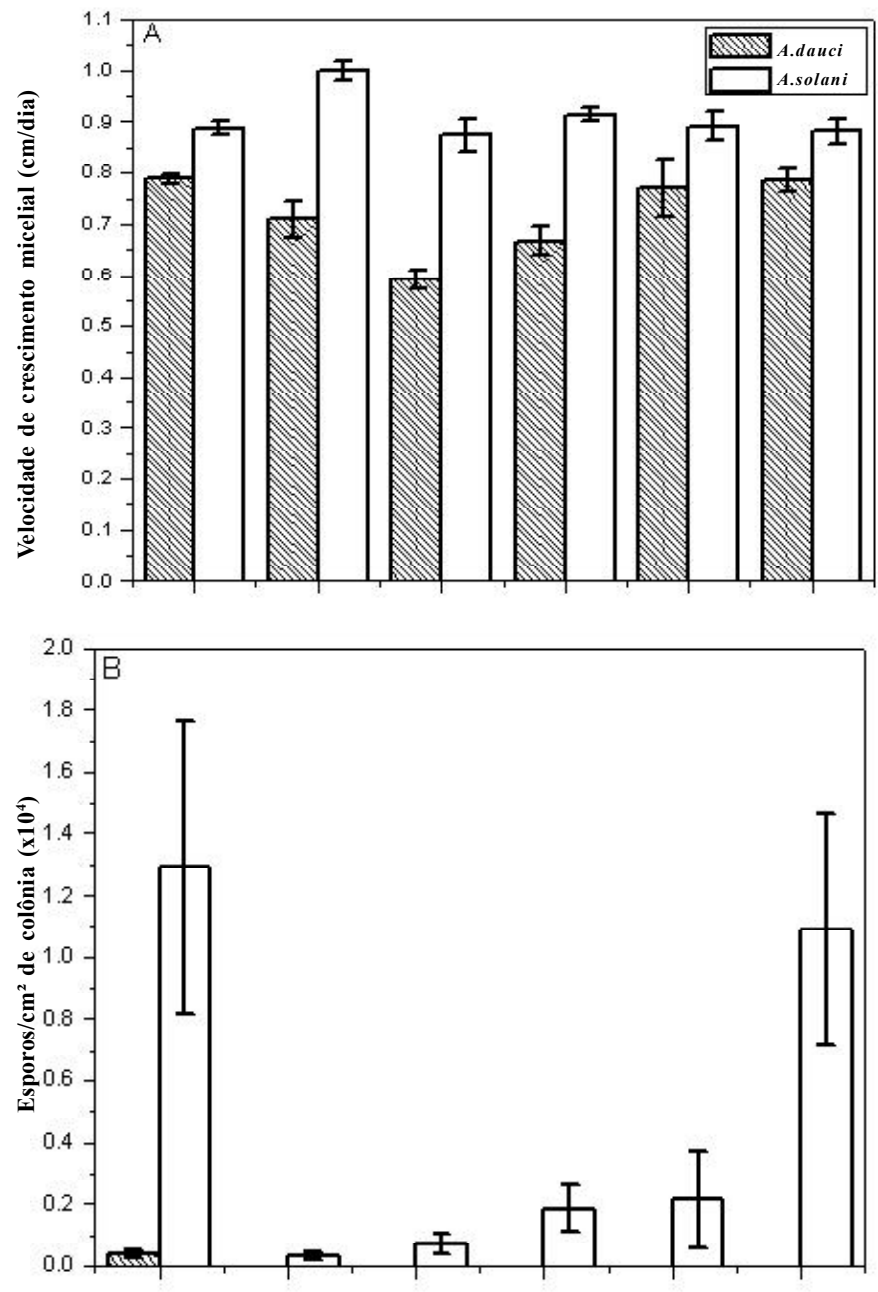

Figura 2 - Efeito de diferentes fontes de luz no crescimento micelial (A) e esporulação (B) de Alternaria dauci e Alternaria solani, cultivadas em meio V8-ágar a $25^{\circ} \mathrm{C}$. As barras representam o erro padrão.

solani. Contudo, este efeito parece ser espécie-dependente, uma vez que para $A$. dauci ele não foi observado.

Os resultados obtidos neste ensaio concordam com Cochrane (2), segundo o qual, a reprodução de vários fungos é iniciada por fatores que paralisam repentinamente o crescimento do micélio previamente estabelecido. Este fato torna-se bastante evidente quando se observa que a remoção completa do micélio aéreo foi o melhor tratamento para a esporulação de ambas as espécies. Além disso, os resultados sugerem a possibilidade de utilização de fatores injuriantes menos comuns na esporulação de espécies de Alternaria, como irradiação de microondas, luz UV e alta temperatura. Em estudos posteriores, esses fatores poderiam ser associados à raspagem do micélio aéreo, para talvez produzir uma esporulação mais profusa. A complexidade e interdependência dos processos metabólicos podem fazer com que os resultados dessa associação sejam benéficos, no que concerne à esporulação.

Efeito do fotoperíodo aplicado após a injúria da colônia na esporulação

Os resultados da esporulação de $A$. dauci, sob influência do fotoperíodo aplicado após a injúria da colônia, estão expostos na Figura 4. Apesar dos diferentes fotoperíodos terem influenciado de 


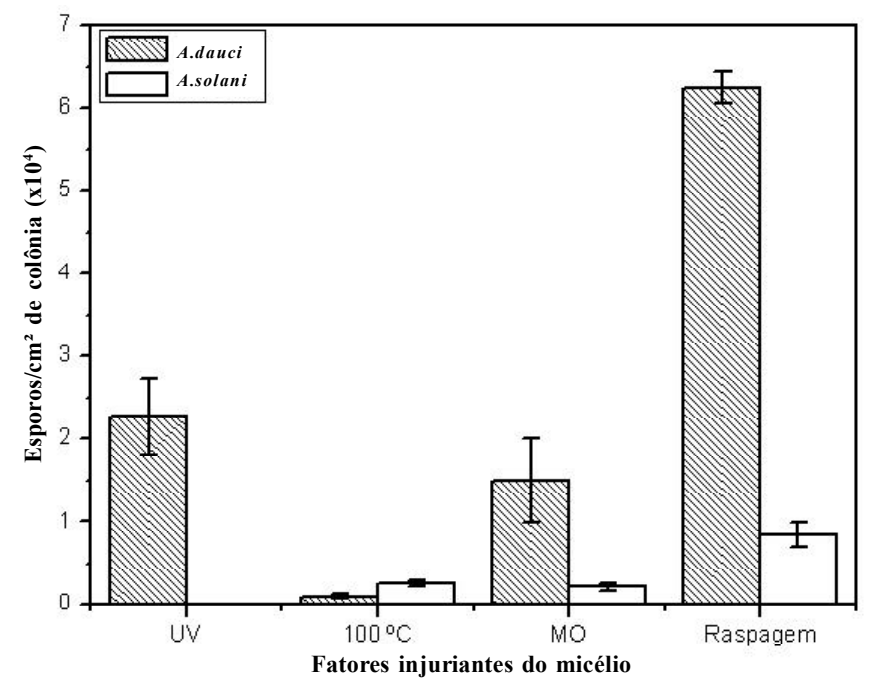

Figura 3 - Efeito de diferentes fatores injuriantes do micélio na esporulação de Alternaria dauci e Alternaria solani cultivadas em meio V8-ágar, a 25 ${ }^{\circ} \mathrm{C}$ e sob luz NUV. As barras representam o erro padrão. UV = radiação ultravioleta, $\mathrm{MO}=$ radiação de microondas.

maneira diferenciada a esporulação desta espécie, não foi observada produção de conídios em nenhum dos tratamentos aplicados à $A$. solani. O isolado desta espécie utilizado no ensaio provavelmente perdeu a capacidade de esporular.

$\mathrm{O}$ fotoperíodo de $12 \mathrm{~h}$ luz / $12 \mathrm{~h}$ escuro foi o que mais influenciou no processo de esporulação de $A$. dauci. Quando houve diminuição das horas de luz para $7 \mathrm{~h}$ e $2 \mathrm{~h}$, também houve uma expressiva esporulação, mas esses dois tratamentos não foram similares. O tratamento com $22 \mathrm{~h} \mathrm{luz} / 2 \mathrm{~h}$ escuro foi o que proporcionou menor esporulação. Nas placas submetidas apenas a 24 de luz ou $24 \mathrm{~h}$ de escuro não foi observada esporulação. Ainda há muita discrepância acerca da esporulação dessas espécies, mas este estudo evidenciou o papel do fotoperíodo na esporulação. Conforme observado nos resultados da Figura 4, é nítido o efeito negativo do aumento no período de luz em detrimento do período de escuro no processo de esporulação. Conforme os resultados observados, este estudo preconiza a utilização

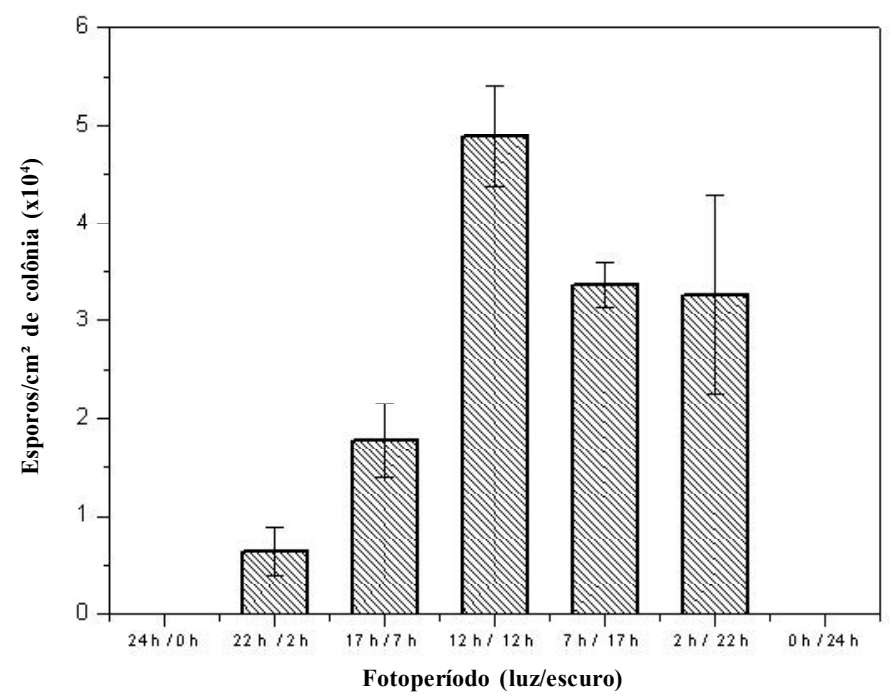

Figura 4 - Efeito do fotoperíodo na esporulação após estresse por raspagem do micélio aéreo de Alternaria dauci, cultivada em meio V8-ágar, a $25^{\circ} \mathrm{C}$ e sob luz NUV. As barras representam o erro padrão. do fotoperíodo de $12 \mathrm{~h} \mathrm{luz} \mathrm{/} 12 \mathrm{~h}$ escuro para estudos de esporulação de A. dauci.

Os resultados obtidos nesse estudo são sustentados pelos estudos de Lukens \& Horsfall (13) que sugerem que a colônia precisa de um período muito pequeno de luz para induzir a formação dos conidióforos, após injúria do micélio. Após iniciada a produção de conidióforos, estes parecem ser capazes de terminar seu desenvolvimento no escuro e logo após começar a produzir esporos.

Comparação entre o método tradicional e o desenvolvido neste estudo, para diferentes isolados de A. dauci e A. solani

O comportamento dos diferentes isolados de A. dauci e A. solani, em relação ao crescimento e esporulação, foi altamente diferenciado para os dois procedimentos avaliados (Figura 5). O crescimento micelial dos isolados de $A$. dauci e $A$. solani sempre foram inferiores quando se utilizou a metodologia tradicional. Na maioria dos isolados, a metodologia desenvolvida neste trabalho apresentou um efeito mais marcante que a tradicional também no que se refere à esporulação de ambas as espécies. Para os isolados que apresentaram esporulação pelo método tradicional, o novo método proporcionou incrementos
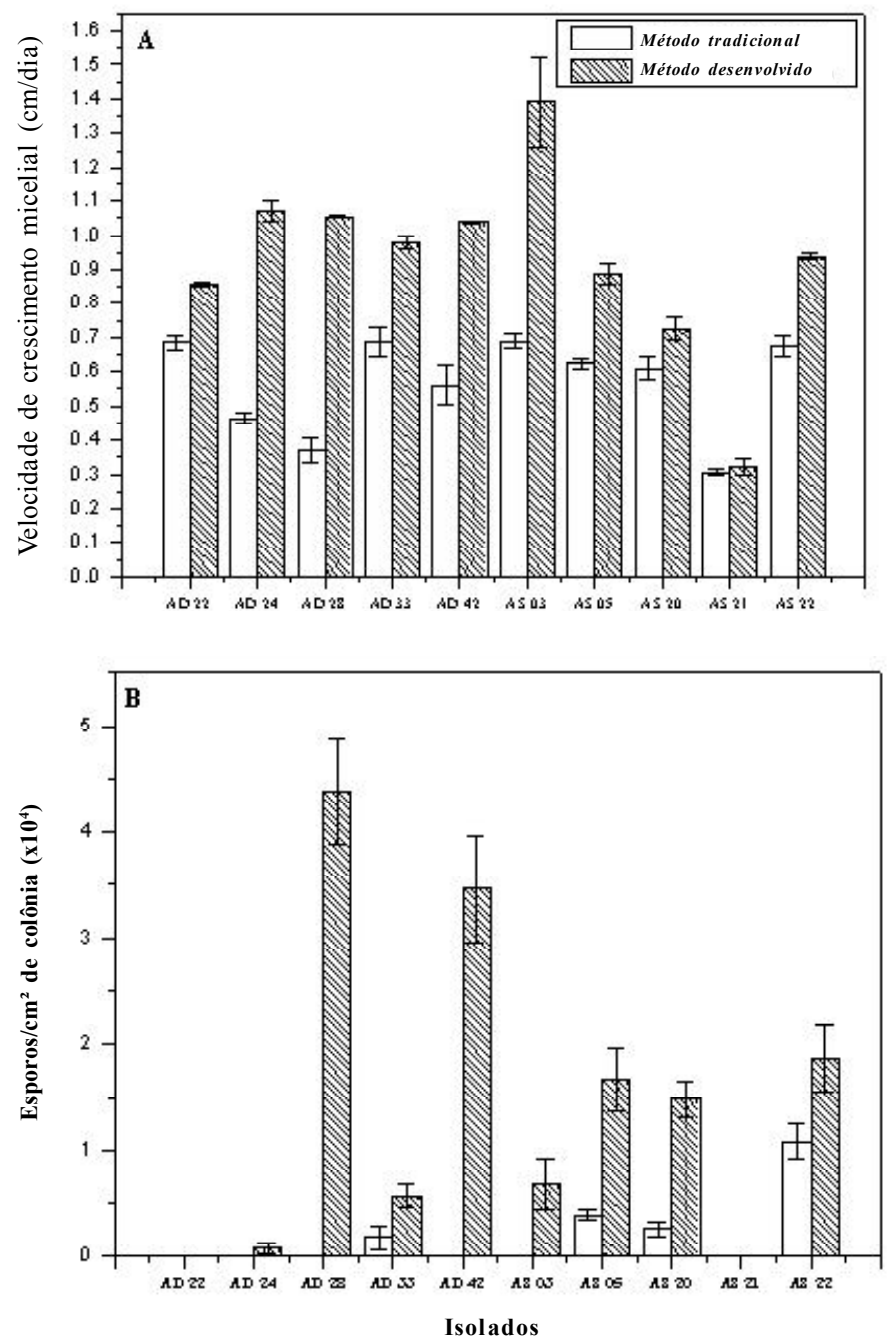

Figuras 5 - Efeito da metodologia tradicional (BDA e luz branca) frente à desenvolvida (V8-ágar e luz NUV), no crescimento micelial (A) e esporulação (B) de Alternaria dauci (AD) e Alternaria solani (AS) cultivadas a $25{ }^{\circ} \mathrm{C}$, sob fotoperíodo de $12 \mathrm{~h}$. As barras representam o erro padrão. 
bastante significativos. Além disso, induziu a esporulação de isolados que não esporularam ou apresentaram precária esporulação pelo método tradicional (Figura 5B). Contudo, a resposta de esporulação foi muito variável, em função do isolado considerado, demonstrando a grande variabilidade para este fator nas espécies estudadas. A grande variação da velocidade de crescimento e esporulação dos isolados, entre os procedimentos, ilustra o comportamento diferenciado e problemático observado em estudos desenvolvidos com essas espécies de Alternaria em meio de cultura. A partir dos resultados obtidos nesse experimento, fica nítido que o conjunto de condições empregadas para a esporulação neste trabalho foi mais eficaz que a metodologia tradicional, para a maioria dos isolados estudados.

O método do meio BDA e luz branca, ainda utilizado por diversos autores para crescimento e esporulação destas duas espécies, mostrou resultados razoáveis e pode ser empregado, desde que os isolados utilizados esporulem nestas condições e que grandes quantidades de esporos não sejam requeridas. Entretanto, quando se usam isolados problemáticos em relação à esporulação, ou quando grandes quantidades de esporos são necessárias, sugere-se utilizar o método aqui desenvolvido, para maiores chances de sucesso.

\section{AGRADECIMENTOS}

Os autores agradecem ao Dr. Ricardo Gioria (Sakata Seed Sudamerica LTDA) por ceder alguns dos isolados utilizados neste trabalho e aos Profs. Drs. Francisco Benedito Teixeira Pessine (UNICAMP), Antonio Simões Pião (UNESP), Ivan Lautenschleguer e Armindo Antonio Alves (UNIARARAS) pela cooperação e sugestões realizadas.

\section{REFERÊNCIAS BIBLIOGRÁFICAS}

1. Caldwell, M.M.; Björn, L.O.; Bornman, J.F.; Flint, S.D.; Kulandaivelu, G.; Teramura, A.H.; Tevini, M. Effects of increased solar ultraviolet radiation on terrestrial ecosystems. Journal of Photochemistry and Photobiology, Oxford, v. 46, n. 1-3, p. 4052,1998 .

2. Cochrane, V.W. Physiology of fungi. New York: John Wiley \& Sons, 1958. 524 p.

3. Dahlberg, K.R., Van Etten, J.L. Physiology and biochemistry of fungal sporulation. Annual Review of Phytopathology, Palo Alto, v. 20, p. 281-301. 1982 .

4. Difco laboratories. Difco manual: dehydrated culture media and reagents for microbiology. 10th ed. Michigan, 1984. 1202 p.

5. Fancelli, M.I. Comparação patogênica, cultural, serológica e eletroforética entre isolados de Alternaria solani do tomate e da batata e variabilidade patogênica de $A$. solani f. sp. lycopersici N. F. 1991. 80 f. Tese (Doutorado em Fitopatologia) - Escola Superior de Agricultura "Luiz de Queiroz", Universidade de São Paulo, Piracicaba, 1991.

6. Fancelli, M.I.; Kimati, H. Influência de meios de cultura e de luz fluorescente na esporulação de Alternaria dauci. Summa Phytopathologica, Piracicaba, v. 16, n. 3-4, p. 248-252,1990.

7. Griffin, D.H. Fungal Physiology. 2nd ed. New York: WilleyLiss, 1994. $456 \mathrm{p}$.

8. Honda, Y.; Nemoto, M. An action spectrum for photoinhibition of conidium formation in the fungus Alternaria solani. Canadian Journal of Botany, Ottawa, v. 62, n. 12, p. 2865-2871, 1984.

9. Kingston, H.M.; Jassie, L.B. Monitoring and predicting parameters in microwave dissolution. In: Jassie, L.B.; Kingston, H.M. Introduction to microwave sample preparation: theory and practice. Washington: ACS, 1998. p. 93-154.

10. Kurozawa, C.; Pavan, M.A. Doenças do tomateiro. In: Kimati, H.; Amorim, L.; Rezende, J.A.M.; Bergamin Filho, A.; Camargo, L.E.A. Manual de Fitopatologia: doenças das plantas cultivadas. 4. ed. São Paulo: Agronômica Ceres, 2005. v. 2, cap. 67, p. 607-626.

11. Leach, C.M. Sporulation of diverse species of fungi under nearultraviolet radiation. Canadian Journal of Botany, Ottawa, v. 40, n. 1, p. 151-161, 1962.

12. Lehninger, A.L. Princípios de bioquímica. 2 ed. São Paulo: Sarvier, 2000. $840 \mathrm{p}$

13. Lukens, R.J.; Horsfall, J.G. Spore initiation in Alternaria solani. Phytopathology, St. Paul, v. 59, n. 8, p. 1039, 1969. (Abstract).

14. Miller, P.M. V-8 juice agar as a general-purpose media for fungi and bacteria. Phytopathology, St. Paul, v. 45, n. 8, p. 461-462, 1955.

15. Queiroz, F.M.; Batista, U.G.; Brommnschenkel, S.H. Avaliação de meios de cultura no crescimento micelial e esporulação de Alternaria brasiliensis. Fitopatologia Brasileira, Brasília, v. 29, n. 5, p. 541-543, 2004.

16. Rotem, J. The genus Alternaria: biology, epidemiology and pathogenicity. 2nd ed. St. Paul: APS Press, 1998. 326 p.

17. Simon, P.W.; Strandberg, J.O. Diallel analysis of resistance in carrot to Alternaria leaf blight. Journal of the American Society for Horticultural Science, Geneva, v. 123, n. 3, p. 412415,1998 .

18. Souza, R.T.; Forcelini, C.A.; Reis, E.M.; Calvete, E.O. Freqüência de Alternaria dauci e Cercospora carotae como agentes da queima das folhas da cenoura em Passo Fundo, RS. Fitopatologia Brasileira, Brasília, v. 26, n. 3, p. 614-618, 2001.

19. Soylu, S.; Kurt, S.; Soylu, E.M.; Tok, F.M. First report of Alternaria leaf blight caused by Alternaria dauci on carrot in Turkey. Plant Pathology, Cambridge, v. 54, n. 2, p. 252, 2005.

20. Strandberg, J.O. Isolation, storage and inoculum production methods for Alternaria dauci. Phytopathology, St. Paul, v. 77, n. 7, p. 1008-1012, 1987.

21. Tuite, J. Plant pathological methods: fungi and bacteria. Minneapolis: Burgess, 1969. 239 p.

22. Turian, G. Sporogenesis in fungi. Annual Review of Phytopathology, Palo Alto, v. 12, p. 129-137, 1974.

23. Zimmer, R.C.; Mckeen, W.E. Interaction of light and temperature on sporulation of the carrot foliage pathogen Alternaria dauci. Phytopathology, St. Paul, v. 59, n. 6, p. 743-749, 1969. 